\title{
Ajuste do processo de micropropagação de barbatimão
}

\author{
Adjustment of the process of micropropagation of Stryphnodendron adstringens (Mart.) Coville
}

\author{
Patrícia Matile Nicioli ${ }^{\mathrm{I}}$ Renato Paiva ${ }^{\mathrm{II}}{ }^{*}$ Raírys Cravo Nogueira ${ }^{\mathrm{II}}$ \\ José Raniere Ferreira de SantanaIII Luciano Coutinho Silva ${ }^{\text {IV }}$ \\ Diogo Pedrosa Corrêa da Silva ${ }^{\mathrm{I}}$ Jorge Marcelo Padovani Porto ${ }^{\mathrm{I}}$
}

\section{RESUMO}

O objetivo desta pesquisa foi determinar um protocolo de micropropagação para o barbatimão. Para indução de brotações, os segmentos nodais foram inoculados em meio de cultura MS com diferentes concentrações de cinetina $\left(0,1,2,3,4\right.$ e $\left.5 \mathrm{mg} \mathrm{L}^{-1}\right)$. Para indução de raízes, brotações obtidas "in vitro" foram inicialmente transferidas para meio MS contendo $50 \%$ da concentração de sais e com diferentes concentrações de ANA (0, 1, 2, 3 e $\left.4 \mathrm{mg} \mathrm{L}^{-1}\right)$. Posteriormente, as brotações foram transferidas para meio MS contendo $50 \%$ da concentração de sais, suplementado com carvão ativado. Para a aclimatização, as plantas obtidas foram transferidas para tubetes contendo diferentes substratos e, então, envolvidas com saco plástico transparente para auxiliar temporariamente na manutenção da umidade. As concentrações de 1 e $5 \mathrm{mg} \mathrm{L}^{-1}$ de cinetina foram as mais eficientes na indução de gemas e brotos, respectivamente. Brotações com maiores comprimentos foram observadas em meio de cultura suplementado com $1 \mathrm{mg} \mathrm{L}^{-1}$ de cinetina. Raízes em maior número e comprimento foram observados em meio de cultura suplementado com $4 \mathrm{mg} \mathrm{L}^{-1}$ de ANA. Os substratos utilizados não afetaram significativamente a taxa de sobrevivência das plantas durante a fase de aclimatização.

Palavras-chave: Stryphnodendron adstringens, cinetina, ANA, aclimatização.

\section{ABSTRACT}

The objective of the research was to determine a micropropagation protocol for the specie Stryphnodendron adstringens (Mart.) Coville. For shoot induction, nodal segments were inoculated in MS medium with different concentrations of kinetin $\left(0,1,2,3,4\right.$ e $\left.5 \mathrm{mg} \mathrm{L}^{-1}\right)$. For root induction, initially the shoots obtained 'in vitro' were transferred to MS containing $50 \%$ of salt concentration and with different concentrations of NAA (0, 1, 2, 3 e $\left.4 \mathrm{mg} \mathrm{L}^{-1}\right)$. Lately, the shoots were moved to MS medium containing $50 \%$ of salt concentration, supplemented with activated charcoal. For acclimatization, the plants obtained were moved to plastic tubes containing different substrates and then covered with transparent plastic bags in order to maintain the environment humidity. The kinetin concentrations of 5.0 and $1.0 \mathrm{mg} \mathrm{L}^{-1}$ were the most efficient for the induction of shots and buds, respectively. Shoot with a higher lengh were observed in MS medium supplemented with $1.0 \mathrm{mg} \mathrm{L}^{-1}$ of kinetin. Roots in a higher number and length were observed in MS medium supplemented with $4.0 \mathrm{mg} \mathrm{L}^{-1}$ of NAA. The substrates used had no significant effect on the rate of plant survival during the acclimatization stage.

Key words: kinetin, NAA, acclimatization.

\section{INTRODUÇÃO}

O barbatimão [Stryphnodendron adstringens (Mart.) Coville] é uma espécie arbórea, de ocorrência nos cerrados, que, além de ser utilizada na recuperação de áreas degradadas apresenta grande valor medicinal, . Entretanto, a cada ano, o extrativismo predatório desta espécie vem aumentando, contribuindo significativamente para a diminuição das populações naturais, fato agravado pela irregularidade no seu processo de germinação e pelo lento desenvolvimento das suas mudas no campo (LORENZI, 2000).

\footnotetext{
'Programa de Pós-graduação em Fisiologia Vegetal, Departamento de Biologia, Universidade Federal de Lavras (UFLA), Lavras, MG, Brasil.

"Departamento de Biologia, Setor de Fisiologia Vegetal, UFLA, Lavras, MG, Brasil. E-mail: renpaiva@ufla.br. *Autor para correspondência.

IIIUniversidade Estadual de Feira de Santana, UEFS, Feira de Santana, BA, Brasil.

${ }^{\mathrm{Iv}}$ Curso de Agronomia, UFLA, Lavras, MG, Brasil.
} 
Como via alternativa de propagação assexuada, a micropropagação por meio da organogênese envolve a diferenciação de brotações e raízes durante o desenvolvimento vegetal. Freqüentemente, as brotações são induzidas em um meio de cultura enriquecido com citocininas e, subseqüentemente, estas brotações são enraizadas em um meio contendo auxina. De acordo com GEORGE (1996), a maioria das plantas micropropagadas é obtida pela multiplicação de brotações axilares.

FRANÇA et al. (1995) promoveram a formação de plantas de barbatimão com a utilização de 6-benzilaminopurina (BAP) e ácido indol-acético (AIA) a partir de segmentos nodais, produzindo cerca de três plantas por explante inicial. No entanto, esta multiplicação necessita de otimização, para incrementar o rendimento de mudas durante a micropropagação.

O objetivo deste trabalho foi avaliar o efeito de diferentes concentrações de cinetina na indução e no crescimento de brotações, do ácido naftaleno acético na indução e no crescimento de raízes e de diferentes substratos na aclimatização de plantas de barbatimão obtidas in vitro, contribuindo para o estabelecimento de um protocolo de micropropagação da espécie.

\section{MATERIAL E MÉTODOS}

Para a indução de brotações em segmentos caulinares de barbatimão, plântulas obtidas da germinação in vitro foram utilizadas como fonte de explantes para este experimento. Segmentos caulinares contendo até duas gemas laterais foram inoculados em meio de cultura MS (MURASHIGE \& SKOOG, 1962) suplementado com diferentes concentrações de cinetina (0, 1, 2, 3, 4 e $\left.5 \mathrm{mg} \mathrm{L}^{-1}\right)$ e 30,0g L ${ }^{-1}$ de sacarose. O meio de cultura foi solidificado com $6 \mathrm{~g} \mathrm{~L}^{-1}$ de ágar e seu $\mathrm{pH}$ foi ajustado para 5,8 antes da autoclavagem a $120^{\circ} \mathrm{C}$ durante 20 minutos. Após a inoculação, os segmentos foram mantidos em sala de crescimento a $25 \pm 2{ }^{\circ} \mathrm{C}$ de temperatura, irradiância de fótons de $36 \mu \mathrm{mol}$ $\mathrm{m}^{-2} \mathrm{~s}^{-1}$ e fotoperíodo de 16 horas.

Aos 60 dias de cultivo, foram avaliados o número de brotações por explante, o comprimento das brotações e o número de gemas da maior brotação. Os dados foram analisados utilizando-se o delineamento inteiramente casualizado, com 12 repetições por tratamento, sendo cada repetição composta por um tubo de ensaio contendo um explante. As variáveis foram analisadas por meio de regressão polinomial e pelo teste de médias Tukey a 5\% de probabilidade.

Para enraizamento in vitro, as brotações obtidas in vitro foram inoculadas em meio de cultura MS com 50\% de sua concentração original e com diferentes concentrações de ácido naftalenoacético ( 0 , 1 , 2, 3 e $4 \mathrm{mg} \mathrm{L} \mathrm{L}^{-1}$ ) e $30 \mathrm{~g} \mathrm{~L}^{-1}$ de sacarose. O meio foi solidificado com $6 \mathrm{~g} \mathrm{~L}^{-1}$ de ágar e seu $\mathrm{pH}$ foi ajustado para 5,8.

Após a inoculação, os explantes foram mantidos em sala de crescimento a $25 \pm 2^{\circ} \mathrm{C}$ de temperatura e na ausência de luz, por 15 dias. Decorrido esse período, eles foram transferidos para meio de cultura MS com 50\% de sua concentração original, sem reguladores de crescimento e com 0,1\% de carvão ativado, permanecendo por mais 30 dias em ambiente escuro. As avaliações foram feitas 30 dias após a segunda inoculação, sendo avaliados o número e o comprimento da maior raiz. Após as avaliações, os explantes foram mantidos em sala de crescimento a 25 $\pm 2^{\circ} \mathrm{C}$ de temperatura, irradiância de fótons de $36 \mu \mathrm{mol}$ $\mathrm{m}^{-2} \mathrm{~s}^{-1}$ e fotoperíodo de 16 horas, por mais 30 dias. Os dados foram analisados utilizando-se o delineamento inteiramente casualizado, com 10 repetições por tratamento, sendo cada repetição composta por um tubo de ensaio contendo um explante. As variáveis foram analisadas por meio de regressão polinomial e pelo teste de médias Tukey a 5\% de probabilidade.

Plantas enraizadas in vitro foram transferidas, após passarem por um período de sete dias de pré-aclimatização (abertura do recipiente de cultivo em sala de crescimento a $25 \pm 2^{\circ} \mathrm{C}$ de temperatura, irradiância de fótons de $36 \mu \mathrm{mol} \mathrm{m} \mathrm{m}^{-2} \mathrm{~s}^{-1}$ e fotoperíodo de 16 horas), para tubetes com volume de $250 \mathrm{~mL}$, contendo Plantmax ${ }^{\circledR}+$ vermiculita na proporção de 1:1 (v/v) e somente Plantmax ${ }^{\circledR}$ e envoltas com sacos plásticos transparentes para manutenção da umidade relativa no ambiente. Durante este período, uma bandeja com água foi colocada em contato com a base dos tubetes visando à manutenção da umidade nos substratos. A bandeja com os tubetes foi mantida em sala de crescimento à temperatura controlada de $25 \pm 2^{\circ} \mathrm{C}$.

Concomitantemente ao controle da umidade relativa e da temperatura, foi realizado o controle da intensidade luminosa, submetendo as plantas a diferentes níveis de irradiância. Assim, nos primeiros sete dias de aclimatização, as plantas foram mantidas sob sombrite $70 \%$ (irradiância de fótons de $\left.10,8 \mu \mathrm{mol} \mathrm{m}^{-2} \mathrm{~s}^{-1}\right)$, seguido por sombrite $50 \%(18 \mu \mathrm{mol}$ $\left.\mathrm{m}^{-2} \mathrm{~s}^{-1}\right), 30 \%\left(25,2 \mu \mathrm{mol} \mathrm{m} \mathrm{m}^{-2} \mathrm{~s}^{-1}\right)$ e, por último, na ausência de qualquer sombrite $\left(36 \mu \mathrm{mol} \mathrm{m} \mathrm{m}^{-2} \mathrm{~s}^{-1}\right)$, permanecendo por sete dias em cada etapa. Durante esse mesmo período, os sacos envoltórios dos tubetes foram sendo perfurados até a remoção completa, visando à redução gradual da umidade relativa. Aos 30 dias, a avaliação de sobrevivência das plantas foi realizada. Os resultados foram analisados utilizando-se o delineamento inteiramente casualizado, com 12 
repetições por tratamento, sendo cada repetição composta por um tubete contendo uma planta. Os dados obtidos foram analisados por meio do teste $\mathrm{F}$.

\section{RESULTADOS E DISCUSSÃO}

Em todas as variáveis analisadas (número de brotações, comprimento e número de gemas da maior brotação), foram encontradas diferenças significativas para as diferentes concentrações de cinetina. Para o número de brotações, à medida que se aumentou a concentração de cinetina, aumentou o número de brotos formados (Figura 1A), e a melhor resposta foi encontrada quando se utilizou $5,0 \mathrm{mg} \mathrm{L}^{-1}$ de cinetina, induzindo, em média, a formação de três brotos por explante. No entanto, como a tendência da resposta foi linear, outros resultados podem ser obtidos em concentrações acima de 5,0mg $\mathrm{L}^{-1}$ de cinetina, como aumento, estabilização ou declínio na produção de brotos. A menor taxa de proliferação de brotos ocorreu no meio sem adição de cinetina (1,25 brotos por explante). Estes dados reforçam a necessidade do uso de citocininas no meio de cultura para a morfogênese in vitro desta espécie, em que a cinetina foi fundamental para uma maior indução de brotações.

Para comprimento da maior brotação, destaca-se o resultado encontrado quando se utilizou uma concentração baixa (1mg L $\mathrm{L}^{-1}$ ) ou a ausência de cinetina, que promoveu crescimento médio de 14 e 13,4mm, respectivamente (Figura 1B). PASQUAL (2001) cita que elevadas concentrações de citocininas podem reduzir o tamanho das brotações e estimular a ocorrência de hiperidricidade e formação de folhas anormais, sendo que estas últimas características não foram observadas nesta pesquisa.

Para a variável número de gemas na maior brotação, houve redução linear com o aumento da concentração da cinetina. O tratamento testemunha apresentou o maior valor, formando, em média, 1,83 gemas por brotação (Figura 1C). Diante disto, pode-se inferir que concentrações mais elevadas de cinetina são eficientes para o aumento do número de novos brotos, enquanto que, contrariamente, concentrações mais baixas ou a ausência deste regulador são fundamentais para promover elongamento e aumento no número de gemas no explante. Assim, os resultados demonstram a eficiência da cinetina para a indução de brotações em barbatimão, havendo, entretanto, necessidade de transferências destas para meio sem regulador de crescimento visando seu alongamento. Além disso, sugere-se testar níveis maiores de cinetina a fim de confirmar a concentração ótima para a maior produção de brotos.
SABÁ et al. (2002), trabalhando com jaborandi (Pilocarpus microphyllus Stapf), verificaram que a combinação de cinetina e zeatina foi mais eficiente na proliferação de brotos a partir de segmento nodal, apresentando 1,0 broto por explante, com tamanho médio de $1,3 \mathrm{~mm}$, enquanto que, a partir de segmento apical, obteve-se, em média 3,0, brotos por explante, com 7,2mm de comprimento, utilizando esses mesmos reguladores.

O protocolo sugerido no presente trabalho é mais viável economicamente que o de FRANÇA et al. (1995), que estimularam a formação de três brotações

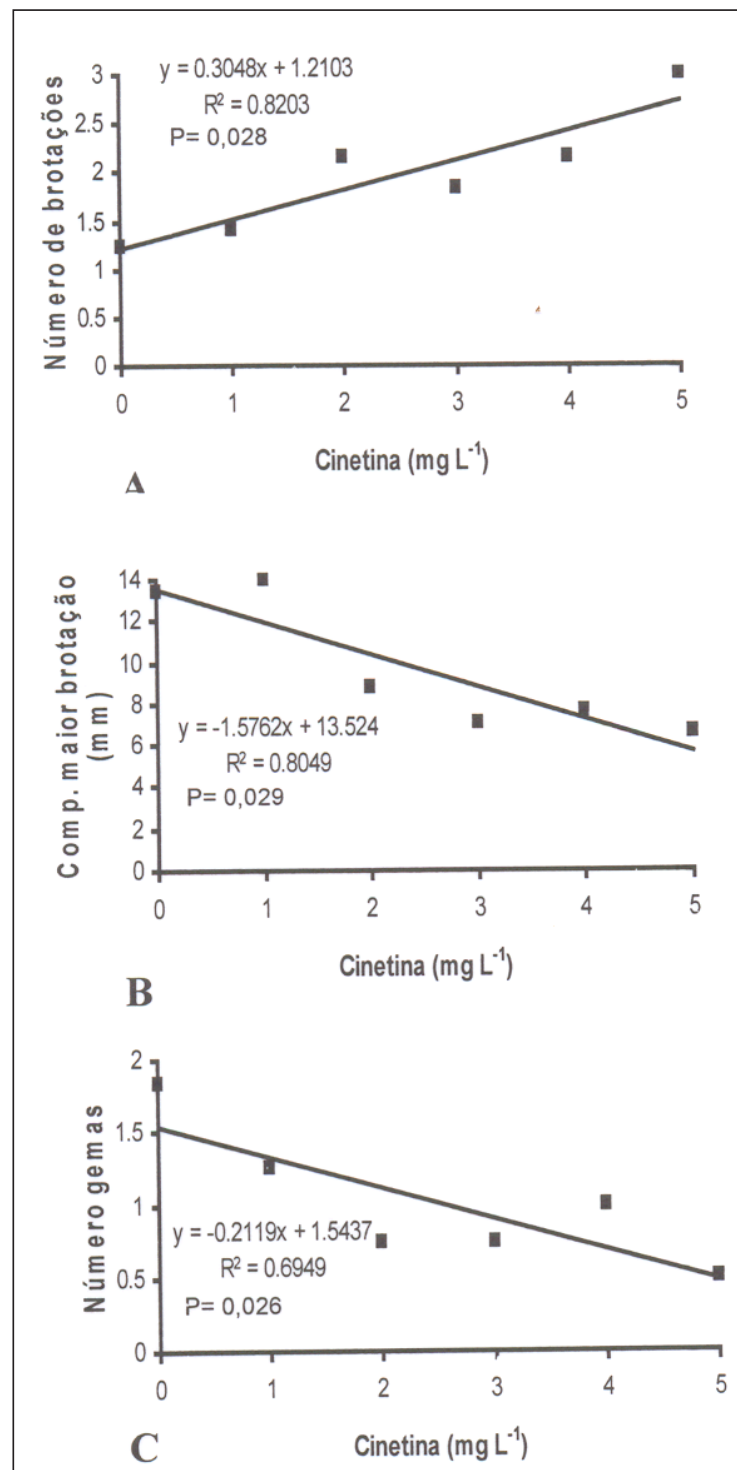

Figura 1 - Número médio de brotações (A), comprimento da maior brotação (B) e número de gemas (C) nos explantes caulinares de barbatimão para cada concentração de cinetina acrescentada ao meio de cultura MS. Lavras, UFLA, 2006.

Ciência Rural, v.38, n.3, mai-jun, 2008. 
por explante inicial com a utilização de 6benzilaminopurina (BAP) e ácido indol-acético (AIA), pois utiliza a cinetina, uma citocinina de preço mais acessível que o BAP, e ANA, uma auxina que não apresenta foto-degradação como o AIA.

Quanto ao efeito do ANA no enraizamento in vitro de brotações, houve diferenças significativas para as variáveis número e comprimento da maior raiz na presença de diferentes concentrações de ANA. As concentrações de 3 e $4 \mathrm{mg} \mathrm{L}^{-1}$ de ANA promoveram os melhores resultados para ambos os parâmetros, formando 1,0 e 1,9 raízes por brotação, com 1,25 e 1,76cm de comprimento, respectivamente (Figura 2). Como houve um incremento linear nestes parâmetros, concentrações acima de $4 \mathrm{mg} \mathrm{L}^{-1}$ de ANA ainda podem ser testadas.

Nos tratamentos sem o regulador de crescimento e com 1 e $2 \mathrm{mg} \mathrm{L}^{-1}$ de ANA, observou-se a formação de raízes muito incipientes (em média, 0,1 raiz por brotação, nos três tratamentos) e estas apresentavam-se mais curtas (em média, 0,05, 0,04 e $0,11 \mathrm{~cm}$, respectivamente), quando comparadas com os valores obtidas nos demais tratamentos. Estes resultados sugerem que os teores endógenos de auxinas, presentes no explante de barbatimão, não foram suficientes para promover a rizogênese em níveis satisfatórios para a aclimatização. Segundo KULESCHA (1988), o nível das auxinas endógenas é o que determina a formação de raízes adventícias.

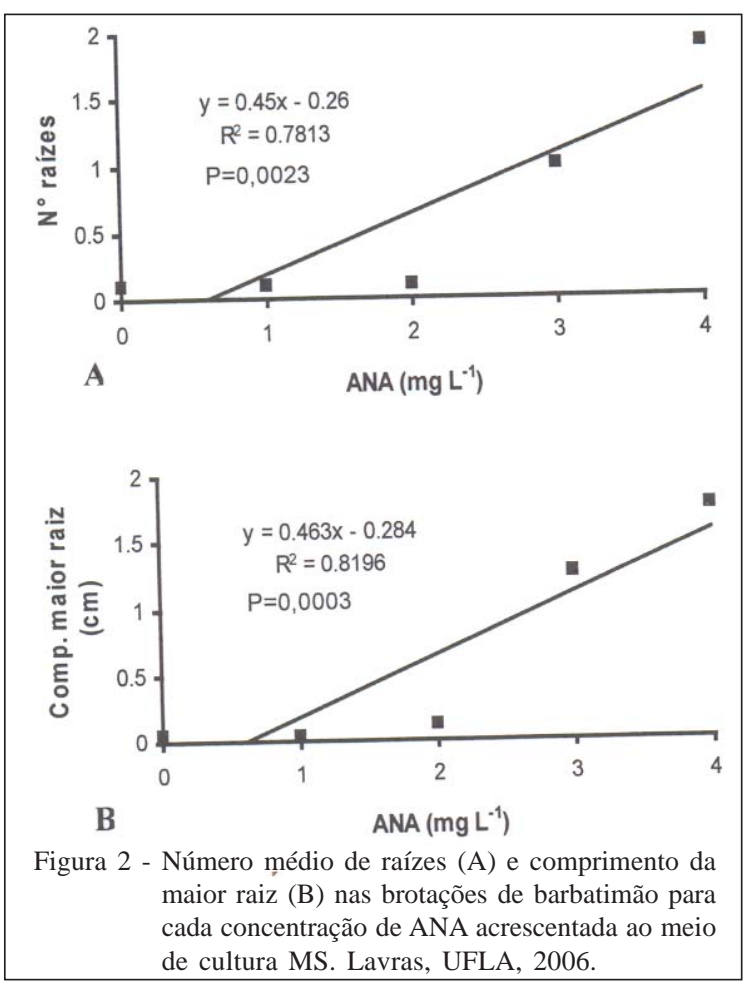

Vale ressaltar que, durante o período de permanência dos explantes na presença de luz (depois de enraizados), o número e o comprimento da maior raiz aumentaram consideravelmente em todos aqueles tratamentos em que o processo de rizogênese já havia iniciado, atingindo 10 raízes com 9,0cm, em média, por brotação. Os resultados deste experimento estão de acordo com os encontrados por LIMA (2004), que constatou melhor eficiência do ANA a $3 \mathrm{mg} \mathrm{L}^{-1}$ sobre o número e comprimentos de raízes em sangra d’água (Croton urucurana Baill.). Já ARAÚJO et al. (2002) verificaram que a utilização de $0,75 \mathrm{mg} \mathrm{L}^{-1}$ de ANA, acrescidos ao meio de cultura MS, viabilizou o início do processo de rizogênese in vitro de babosa (Aloe vera), assim como MOURA et al. (2001) obtiveram enraizamento de Citrus com índice de 80\%, trabalhando com ANA na concentração de $1 \mathrm{mg} \mathrm{L}^{-1}$.

A utilização do ANA, em concentrações variando de 0,5 a 5,0mg $\mathrm{L}^{-1}$, também foi fundamental para enraizar brotos de laranja-doce "Pineapple", com índice de 85\% (DURAN-VILA et al., 1989); de lima ácida "Galego", com 70\% (PERES-MOLPHE-BALCH \& OCHOA-ALEJO, 1997) e citrange “Troyer”, com 86\% (MOREIRA-DIAS et al., 2000).

Na fase de aclimatização de plantas cultivadas in vitro, a proporção de plantas sobreviventes nos dois tratamentos (somente Plantmax ${ }^{\circledR}$ e vermiculita + Plantmax ${ }^{\circledR}$ ) foi similar, não diferindo significativamente. As plantas de barbatimão aclimatizadas em Plantmax apresentaram 50\% de sobrevivência e as aclimatizadas em vermiculita + Plantmax ${ }^{\circledR}, 41 \%$, após um período de 30 dias em sala de crescimento, com redução gradual do sombrite e abertura parcial dos sacos plásticos que envolviam os tubetes. Também não foram detectadas diferenças em tamanho e aspecto visual das plantas ao final do período de avaliação, nos dois tipos de substratos.

DZAZIO et al. (2002), estudando o efeito de três substratos (Vermiculita, Plantmax ${ }^{\circledR}$ e casca de arroz carbonizada) na aclimatização do porta-enxerto de videira “420-A", obtiveram $95,83 \%$ e $87,50 \%$ de sobrevivência para os substratos vermiculita e Plantmax $^{\circledR}$, respectivamente. O menor índice de sobrevivência das brotações foi obtido no substrato com casca de arroz, em que apenas $45,83 \%$ das brotações sobreviveram.

Vale ressaltar que a redução no número de plantas sobreviventes ocorreu após a retirada total do saco plástico envoltório dos tubetes, aos 21 dias após o início da aclimatização (a sobrevivência decresceu de $90 \%$ e $80 \%$ para $50 \%$ e $41 \%$ nos tratamentos Plantmax ${ }^{\circledR}$ e vermiculita + Plantmax ${ }^{\circledR}$, respectivamente). Este fato se deve, em grande parte, à mudança das 
condições ambientais as quais as plântulas estavam submetidas, principalmente a umidade relativa, que era maior no interior do saco plástico e mais próximo daquela encontrada no interior do tubo de ensaio.

Com base nestes resultados, por um lado sugere-se que o tipo de substrato utilizado tem pouca relevância no processo de aclimatização de plantas de barbatimão. Por outro lado, o controle da umidade do ar durante esta fase parece ser preponderante, buscando-se o desenvolvimento de protocolos mais eficientes.

\section{CONCLUSÕES}

As concentrações de $5 \mathrm{mg} \mathrm{L}^{-1}$ de cinetina e de $4 \mathrm{mg} \mathrm{L}^{-1}$ de ANA são as mais indicadas na indução de multibrotações e de maior número de raízes, respectivamente, a partir de segmentos nodais de barbatimão.

A utilização de Plantmax ${ }^{\circledR}$ ou vermiculita + Plantmax ${ }^{\circledR}$ promovem efeitos similares no processo de aclimatização dessa espécie.

\section{AGRADECIMENTOS}

Ao Laboratório de Cultura de Tecidos de Plantas, Setor de Fisiologia Vegetal, da Universidade Federal de Lavras (UFLA), pela execução da pesquisa. À Fundação de Amparo à Pesquisa do Estado de Minas Gerais (FAPEMIG), pelo apoio financeiro e concessão de bolsa a Luciano Coutinho Silva e à Raírys Cravo Nogueira. Ao Conselho Nacional de Desenvolvimento Científico e Tecnológico (CNPq) e à Coordenação de Aperfeiçoamento de Pessoal de Nível Superior (CAPES), pela concessão de bolsa aos pós-graduandos Patrícia Matile Nicioli, Diogo Pedrosa Corrêa da Silva e Jorge Marcelo Padovani Porto.

\section{REFERÊNCIAS}

ARAÚJO, P.S. et al. Micropropagação de babosa (Aloe VeraLiliaceae). Biotecnologia Ciência \& Desenvolvimento, n.25, p.54-57, 2002.

DURAN-VILA, N., et al. Morphogenesis and tissue culture of three citrus species. Plant Cell, Tissue and Organ Culture, v.16, p.123-133, 1989.
DZAZIO, P.M., et al. Micropropagação do porta-enxerto de videira '420-A'. Revista Brasileira de Fruticultura, v.24, n.3, p.759-764, 2002.

FRANÇA, S.C. et al. Micropropagation of Stryphnodendrons polyphythum (Barbatimão). Plant Cell, Tissue and Organ Culture, v.42, p.291-293, 1995.

GEORGE, E.F. Plant propagation by tissue culture: part 1 - the technology. Edington: Exegetics, 1996. 1574p.

KULESCHA, Z. Recherches sur l'élaboration de substances de croissance of micropropagation. Acta Horticulturae, n.230, p.63-71, 1988.

LIMA, E.C. Micropropagação, calogênese e anatomia foliar de sangra d’água (Cróton urucurana BAILL.). 2004. 105f. Dissertação (Mestrado em Agronomia Fisiologia Vegetal) - Curso de Pós-graduação em Agronomia Fisiologia Vegetal, Universidade Federal de Lavras.

LORENZI, H. Árvores brasileiras: manual de identificação e cultivo de plantas arbóreas nativas do Brasil. Nova Odessa: Plantarum, 2000. v.1, 370p.

MOREIRA-DIAS, J.M. et al. Direct and indirect shoot organogenic pathways in epicotyl cuttings of Trayer citrange differ in hormone requirements and their response to light. Annals of Botany, v.85, p.103-110, 2000.

MOURA, T.L. de et al. Organogênese in vitro de Citrus em função de concentrações de BAP e seccionamento de explantes. Revista Brasileira de Fruticultura, SP, v.23, n.2, p.240245, 2001.

MURASHIGE, T.; SKOOG, F. A revised medium for rapid growth and bioassays with tobacco tissue cultures. Physiologia Plantarum, v.15, n.3, p.473-497, 1962.

PASQUAL, M. Textos acadêmicos: meios de cultura. Lavras: FAEPE/UFLA, 2001. 127p.

PERES-MOLPHE-BALCH, E.; OCHOA-ALEJO, N. In vitro plant regeneration of Mexican lime and Mandarim by direct organogenesis. HortScience, v.32, n.5, p.931-934, 1997.

SABÁ, R.T. et al. Micropropagação do jaborandi. Horticultura Brasileira, v.20, n.1, p.106-109, 2002. 